\title{
OCENA ODPORNOŚCI DYNAMICZNEJ ŻELIWA ADI Z DODATKIEM MIEDZI I MOLIBDENU
}

\begin{abstract}
Materiały inżynierskie wykorzystywane w licznych zastosowaniach, w szczególności w motoryzacyjnych i wojskowych, muszą sprostać nowym wymaganiom, z których jednym z najważniejszych jest odporność na obciążenia dynamiczne. Ponieważ zjawiska związane z takimi interakcjami są dość złożone, stosuje się niestatyczne typy testów do oceny i porównania różnych potencjalnych materiałów. W pracy tej dwa rodzaje żeliwa ADI wytworzono w różnych warunkach austenityzowania i hartowania, otrzymując różną morfologię ausferrytu. Próbki z obu materiałów były poddawane różnym dynamicznym szybkościom odkształcania. Oceniono odporność na martenzytyczną przemianę odkształceniową w zależności od mikrostruktury i szybkości odkształcania. Badania XRD i LM były wykorzystane do oceny właściwości oraz wpływu dużych szybkości odkształcania na strukturę materiału.
\end{abstract}

Słowa kluczowe: żeliwo sferoidalne ausferrytyczne, test Taylora, odporność na obciążenia dynamiczne, przemiana odkształceniowa

\section{Wprowadzenie}

Żeliwo sferoidalne ausferrytyczne (ang. Austempered Ductile Iron - ADI) jest materiałem konstrukcyjnym, który ciągle wzbudza ciekawość naukowców oraz zainteresowanie praktyków, konstruktorów i użytkowników. Może właśnie dlatego wciąż pojawiają się nowe pomysły i badania naukowe zmierzające do uszlachetniania jego właściwości $[1,2]$. Jest to szczególnie ważne w aspekcie wdrożeń i zastosowania ADI.

Żeliwo sferoidalne ausferrytyczne jest materiałem sklasyfikowanym według normy europejskiej i amerykańskiej [3, 4]. Charakterystyczną cechą tego materiału jest połączenie dobrych właściwości plastycznych i wytrzymałościowych, porównywalne do wielu gatunków stali $[4,5]$. Właściwości najlepiej poznane to: zdolność do tłumienia drgań, o 10\% mniejsza gęstość w porównaniu ze stalą,

1 Autor do korespondencji/corresponding author: Dawid Myszka Politechnika Warszawska, ul. Narbutta 85, 02-524 Warszawa, tel.: 22 8499797, mail: d.myszka@ wip.pw.edu.pl

${ }^{2}$ Mostafa Ahmed, Central Metallurgical Research and Development Institute, Cairo, Egypt, e-mail: Mostafa.Aothman@hotmail.com

${ }^{3}$ Leszek Cybula, Politechnika Warszawska, e-mail: 1.cybula@wip.pw.edu.pl 
dobra skrawalność przed obróbką cieplną, zdolność do umacniania powierzchni odlewów podczas walcowania lub kulowania itp. Ta ostatnia cecha wiąże się z obecnością w strukturze ADI austenitu niestabilnego mechanicznie, który ma zdolność do transformacji w twardy martenzyt podczas odkształcania. Analiza takiego austenitu jest jednym z najciekawszych aspektów analizowanych obecnie w literaturze, ponieważ właśnie w jej obecności w strukturze doszukuje się bardzo dobrej odporności na obciążenia dynamiczne żeliwa sferoidalnego poddanego obróbce cieplnej.

Statyczne warunki odkształcenia pozwalają na scharakteryzowanie mechanizmów przemiany austenitu niestabilnego mechanicznie. Bliższe rzeczywistym warunkom przemiany odkształceniowej austenitu w martenzyt są jednak oddziaływania dynamiczne. Podjęto zatem badania nad wpływem różnej szybkości odkształcenia żeliwa sferoidalnego ausferrytycznego na przemiany jego mikrostruktury za pomocą metody Taylora.

\section{Metodyka badań}

Materiał użyty w badaniach uzyskano w eksperymentalnej odlewni Centralnego Instytutu Metalurgii Badań i Rozwoju (CMRDI) w Egipcie, wykorzystując piec indukcyjny o średniej częstotliwości, pojemności $100 \mathrm{~kg}$. Skład chemiczny żeliwa sferoidalnego był następujący: $3,84 \% \mathrm{C}, 2,63 \% \mathrm{Si}, 0,02 \% \mathrm{~S}, 0,015 \% \mathrm{P}$, $0,04 \% \mathrm{Mg}, 0,2 \% \mathrm{Mn}, 0,6 \% \mathrm{Cu}, 0,25 \% \mathrm{Mo}$, reszta $-\mathrm{Fe}$. Materiał został pierwotnie odlany w postaci bloków Y o grubości podstawy $25 \mathrm{~mm}$. Na próbkach wyciętych z odlewów przeprowadzono obróbkę cieplną, w której próbki austenityzowano w $900^{\circ} \mathrm{C}$ przez $45 \mathrm{~min}$, a następnie hartowano izotermicznie w kąpieli solnej w 275 i $375^{\circ} \mathrm{C}$ przez 45 min (ADI-275 oraz ADI-375). Mikrostrukturę próbek z żeliwa sferoidalnego przed i po obróbce cieplnej przedstawiono na zdjęciach (rys. 1. i 2.).

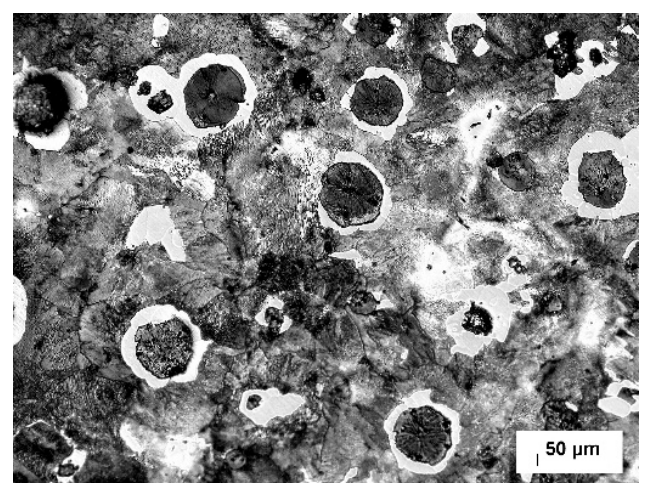

Rys. 1. Mikrostruktura postodlewnicza żeliwa sferoidalnego poddanego badaniom

Fig. 1. As-cast microstructure of the investigated ductile iron 
a)

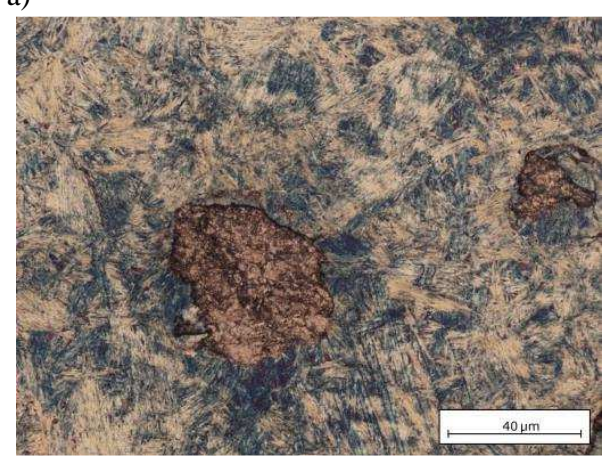

b)

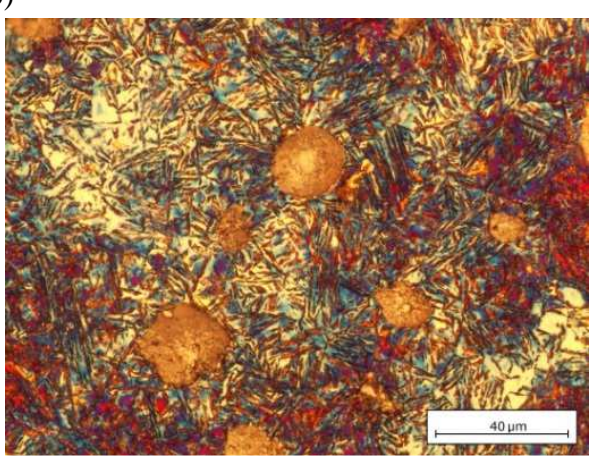

Rys. 2. Mikrostruktura żeliwa sferoidalnego po obróbce cieplnej: a) ADI-275, b) ADI-375

Fig. 2. Microstructure of heat treated ductile iron: a) ADI-275, b) ADI-375

Na przygotowanych próbkach wykonano serię badań właściwości mechanicznych w statycznej próbie rozciągania, pomiarów twardości oraz ocenę składu fazowego XRD (tab. 1.). Przeprowadzono także test Taylora dla dwóch prędkości odkształcenia: 180 oraz $230 \mathrm{~m} / \mathrm{s}$. Test ten zakłada dynamiczną deformację cylindrycznej próbki, która uderza z założoną prędkością w nieodkształcalną przegrodę (rys. 3.). Parametry uderzenia oraz stopień deformacji próbki, który jest możliwy do określenia za pomocą geometrycznych pomiarów, są miarą dynamicznych właściwości badanego materiału. Zastosowanie wyznaczonych w teście parametrów uderzenia oraz stopnia deformacji próbki do zależności wyprowadzonej przez Taylora pozwala na wyznaczenie tzw. dynamicznej granicy plastyczności $[5,6]$. Właściwość ta umożliwia porównanie różnych materiałów $\mathrm{w}$ warunkach dynamicznych obciążeń przez ocenę możliwości odkształcenia części czołowej próbki (grzybkowania) lub jej fragmentacji.

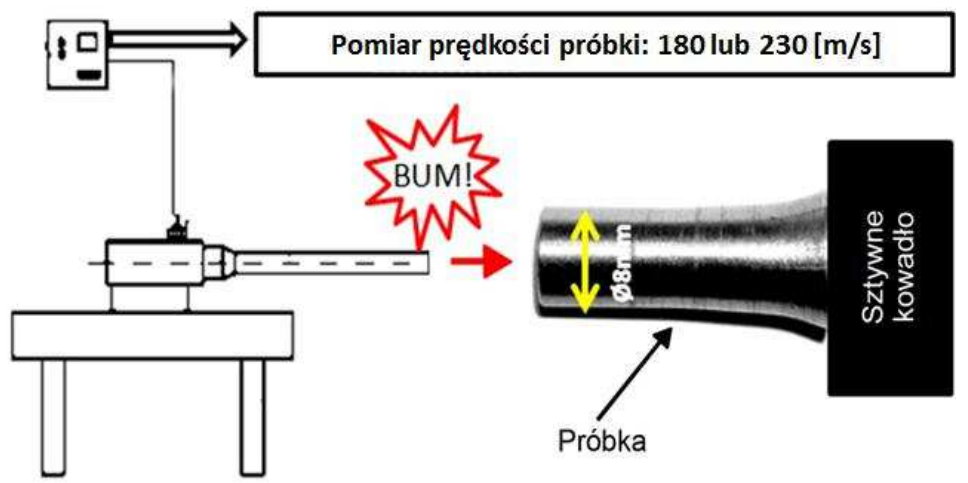

Rys. 3. Schemat dynamicznego odkształcenia próbki w metodzie Taylora

Fig. 3. Schematic representation of the dynamic deformation of sample in a Taylor test 
Tabela 1. Właściwości statyczne żeliwa sferoidalnego poddanego badaniom

Table 1. Static properties of the tested austempered ductile iron

\begin{tabular}{|c|c|c|c|c|}
\hline Materiał & $\begin{array}{c}\text { Udział } \\
\text { austenitu } \\
{[\%]}\end{array}$ & $\begin{array}{c}\text { Twardość } \\
{[\mathrm{HV}]}\end{array}$ & $\begin{array}{c}\text { Granica } \\
\text { plastyczności, } \\
\mathrm{R}_{\mathrm{p} 0,2}[\mathrm{MPa}]\end{array}$ & $\begin{array}{c}\text { Udarność } \\
\text { (bez karbu) } \\
\mathrm{K}[\mathrm{J}]\end{array}$ \\
\hline ADI-375 & 41,8 & 300 & 871 & 60 \\
\hline ADI-275 & 16,3 & 428 & 1341 & 45 \\
\hline
\end{tabular}

\section{Wyniki i dyskusja}

Z punktu widzenia odkształceniowej przemiany martenzytycznej podczas testu Taylora zachodzą równocześnie dwa zjawiska oddziaływania na mikrostrukturę, tj. przez falę sprężystą i plastyczną. Jeśli zatem przemiana będzie zachodzić, to uwzględniając dużą szybkość odkształceń, będzie można ją również zaobserwować na przekroju próbki. Skutki przemiany odkształceniowej powinny być widoczne w materiale od czoła próbki aż do zaniku uruchamiających ją naprężeń ściskających. Doświadczenia przeprowadzone na wybranych próbkach z żeliwa sferoidalnego ausferrytycznego [6] dokumentują, że martenzyt pojawia się w strefie oddziaływania fali plastycznej. Całkowita przemiana austenitu niestabilnego mechanicznie zachodzi jednak jedynie w strefie najsilniejszego zgniotu, tzn. do głębokości ok. $3 \mathrm{~mm}$ od powierzchni uderzenia (rys. 4.). Ocena morfologii grafitu

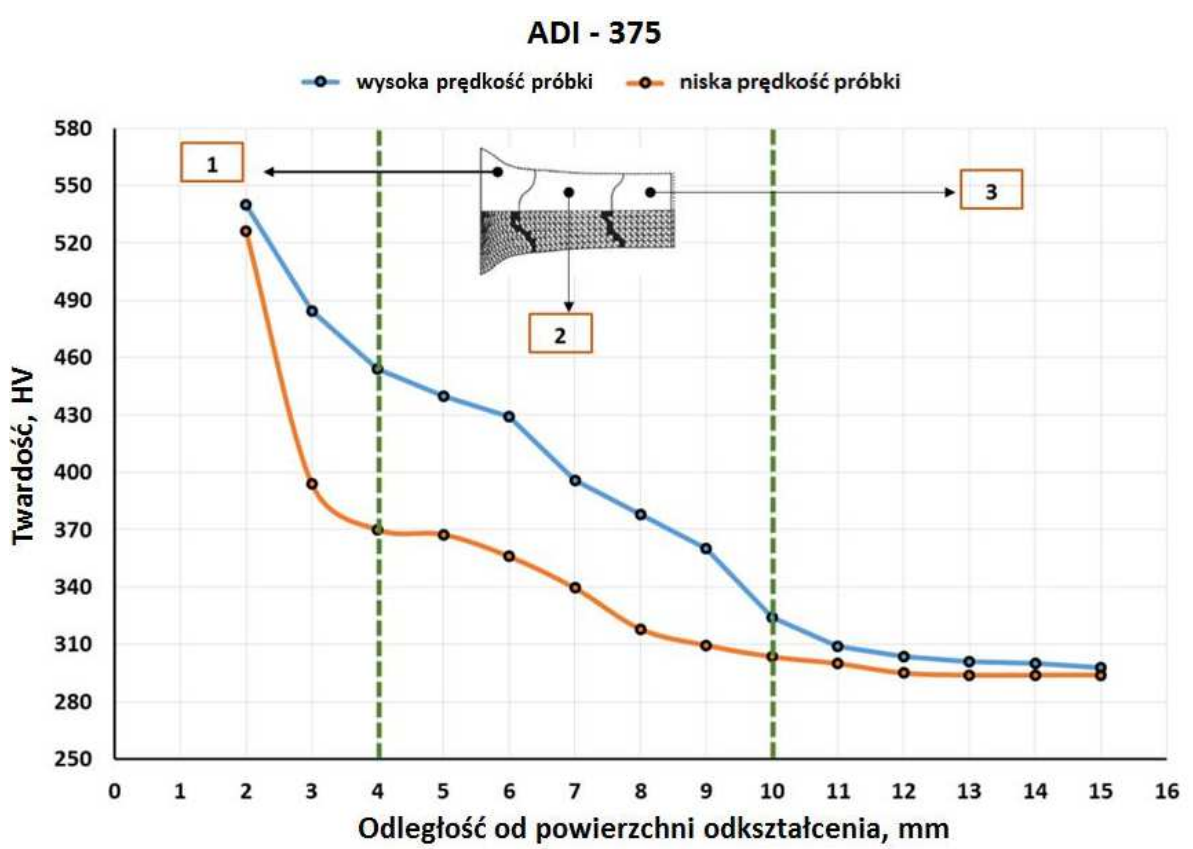

Rys. 4. Mikrotwardość na przekroju próbek ADI-375 dla niskiej i wysokiej prędkości uderzenia

Fig. 4. Microhardness profiles of ADI-375 at low and high velocity impact 
umożliwia stwierdzenie, że strefa ta była odkształcona do wartości powyżej 50\%. Martenzyt pojawia się przede wszystkim w warstwie wierzchniej (rys. 4.), ale również w głębszych strefach próbek, gdzie przemiana zachodzi tylko częściowo. Zbyt duże odkształcenia próbek uderzających w kowadło z prędkością większą niż $200 \mathrm{~m} / \mathrm{s}$ mogą powodować naruszenie spójności w obszarach objętych adiabatycznymi pasmami ścinania, co jest widoczne dla próbki ADI-275 (tab. 2.).

Tabela 2. Właściwości dynamiczne żeliwa sferoidalnego poddanego badaniom

Table 2. Dynamic properties of the tested austempered ductile iron

\begin{tabular}{|c|c|c|c|c|c|c|}
\hline \multirow{2}{*}{ Materiał } & \multicolumn{2}{|c|}{$\begin{array}{c}\text { Dynamiczna granica } \\
\text { plastyczności } \\
\mathrm{R}_{\mathrm{d}}[\mathrm{MPa}]\end{array}$} & $\mathrm{R}_{\mathrm{d}} / \mathrm{R}_{\mathrm{p} 0,2}$ & \multicolumn{2}{|c|}{$\begin{array}{c}\text { Dynamiczna granica } \\
\text { plastyczności } \\
\mathrm{R}_{\mathrm{d}}[\mathrm{MPa}]\end{array}$} & $\mathrm{R}_{\mathrm{d}} / \mathrm{R}_{\mathrm{p} 0,2}$ \\
\cline { 2 - 7 } & \multicolumn{2}{|c|}{ niska prędkość uderzenia $\approx 180 \mathrm{~m} / \mathrm{s}$} & \multicolumn{2}{c|}{ wysoka prędkość uderzenia $\approx 230 \mathrm{~m} / \mathrm{s}$} \\
\hline ADI-375 & 1352,5 & grzybkowanie & 1,6 & 1201,6 & grzybkowanie & 1,4 \\
\hline ADI-275 & 2182,3 & grzybkowanie & 1,6 & - & fragmentacja & - \\
\hline
\end{tabular}

Aby potwierdzić zależność tworzenia się martenzytu od przemiany odkształceniowej, udziały austenitu oraz martenzytu w mikrostrukturze próbek ADI-275 i ADI 375 po teście Taylora zostały określone przez pomiary XRD. Dodatkowo wykonano profil mikrotwardości wzdłuż osi próbki i obserwacje mikrostruktury trawionej na gorąco, umożliwiającej kolorową identyfikację martenzytu (błękitna faza na rys. 5.).

a)

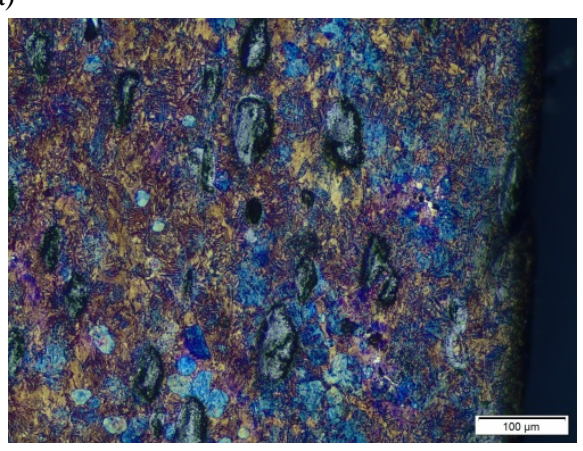

b)

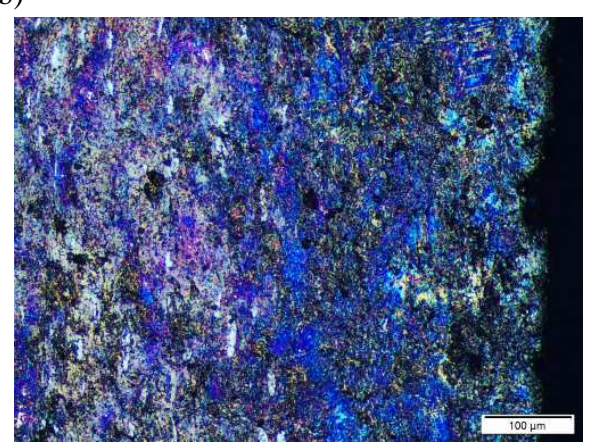

Rys. 5. Mikrostruktura w warstwie odkształconej na przekroju próbek ADI-375 dla (a) niskiej i (b) wysokiej prędkości uderzenia - strefa 1: a) 18,4\% martenzytu, b) 27,2\% martenzytu; trawienie nitalem na gorąco według zastrzeżonej procedury

Fig. 5. Microstructure in the deformed surface layer on profiles of ADI-375 at (a) low and (b) high velocity impact - zone 1: a) 18,4\% of martensite, b) 27,2\% of martensite; hot nital etching according to the proprietary procedure 
Mikrostruktura, profil mikrotwardości i badania rentgenowskie XRD próbki ADI-375 (rys. 4. i 5.) wskazują na zwiększający się udział martenzytu w strefie grzybkowania - strefa 1. Dyfraktogramy XRD pokazują, że próbka ADI-375 posiada w strefie 3. (rys. 4.) ok. 1,2\% martenzytu i ok. 41,8\% austenitu w pierwotnej strukturze ausferrytu przed uderzeniem. Po silnym zdeformowaniu, w strefie 1 . udział martenzytu w próbce ADI-375 znacznie wzrasta wraz ze wzrostem prędkości uderzenia i ostatecznie osiąga odpowiednio 18,4 i 27,2\% przy niskiej i wysokiej prędkości uderzenia. W próbce ADI-275 w nieodkształconej strefie 3. znajduje się $8,3 \%$ zawartości martenzytu, natomiast cały austenit w strukturze strefy 1. (ok. $17 \%$ ) został poddany odkształceniowej przemianie martenzytycznej, aby osiągnąc całkowity poziom $24 \%$ martenzytu. Jest to poziom zbliżony do udziału martenzytu ujawnionego w próbce ADI-375 w tej samej strefie.

\section{Wnioski}

Wyniki przedstawione w artykule potwierdzają silny wpływ przemiany odkształceniowej na właściwości badanych próbek ADI-275 i ADI-375, a tym samym żeliwa sferoidalnego charakteryzującego się różnym udziałem austenitu niestabilnego mechanicznie w strukturze osnowy. Stwierdzono również wysoką odporność żeliwa sferoidalnego ausferrytycznego na obciążenia dynamiczne i jego przydatność w wysoko obciążonych konstrukcjach maszyn i urządzeń.

\section{Literatura}

[1] Nofal A.: Advances in the metallurgy and applications of ADI, J. Metall. Eng., 2 (2013) 1-18.

[2] Guzik E.: Procesy uszlachetniania żeliwa - wybrane zagadnienia, Archiwum Odlewnictwa PAN, monografia nr 1, Katowice 2001.

[3] PN-EN 1564/2012 - Odlewnictwo - Żeliwo sferoidalne ausferrytyczne.

[4] Hayrynen K.L., Keough J.R., Pioszak G.L.: AFS Proceedings, IL USA 2010.

[5] Wieczorek A.N.: Comparative studies on the wear of ADI alloy cast irons as well as selected steels and surface-hardened alloy cast steels in the presence of abrasive, Arch. Metall. Mater., 62 (2017) 119-128.

[6] Myszka D., Cybula L., Wieczorek A.: Influence of heat treatment conditions on microstructure and mechanical properties of austempered ductile iron after dynamic deformation test, Arch. Metall. Mater., 59 (2014) 1181-1189.

\section{EVALUATION OF DYNAMIC RESISTANCE OF ADI WITH ADDITION OF COPPER AND MOLYBDENIUM}

\section{S u m m a r y}

Engineering materials used in numerous applications, in particular in automotive and military applications, have to meet new requirements, one of the most important being resistance to dynamic loads. Because the phenomena associated with such interactions are quite complex, non-static test 
types are used to evaluate and compare different potential materials. In this work, two types of ADI cast iron were made in different austenitizing and quenching conditions to obtain different ausferrite morphology. Samples from both materials were subjected to different dynamic deformation rates. The resistance to martensitic strain transformation was evaluated depending on the microstructure and rate of deformation. XRD and LM were used to assess the properties and impact of high strain rates on the material structure.

Keywords: austempered ductile iron, Taylor test, impact resistance, strain transformation

DOI: $10.7862 / \mathrm{rm} .2018 .32$

Przestano do redakcji: 23.04 .2018

Przyjęto do druku: 28.06.2018 
